\title{
Model presoje poslovne uspešnosti in izkoriščenosti zmogljivosti v bolnišnicah
}

UDK: 005.336.1:614.21(045)

Petra Došenovič Bonča

Ekonomska fakulteta Univerze v Ljubljani petra.d.bonca@ef.uni-lj.si

Maks Tajnikar

Ekonomska fakulteta Univerze v Ljubljani maks.tajnikar@ef.uni-lj.si

\section{IZVLEČEK}

Pri presoji poslovne uspešnosti bolnišnic običajno uporabljamo nabor kazalnikov in kazalcev, ki bodisi v obliki odnosov med kategorijami bodisi v obliki absolutnih vrednosti izražajo poslovno uspešnost. Takšne kazalnike in kazalce poslovne uspešnosti zelo pogosto dopolnjujemo s kazalniki učinkovitosti, ki odražajo zlasti vidik izkoriščenosti človeških in materialnih zmogljivosti in s tem vsaj delno pojasnjujejo kazalnike poslovne uspešnosti. $V$ tej razpravi prikazujemo, da je analiza poslovne uspešnosti bolnišnic na podlagi standardnih kazalnikov in kazalcev pomanjkljiva, in pojasnimo, da lahko presojo poslovne uspešnosti in učinkovitosti v bolnišnicah izboljšamo $z$ uporabo procesnega modela.

Ključne besede: bolnišnica, presoja poslovne uspešnosti, procesni model. JEL : 119

\section{Uvod}

Pri analizi poslovne uspešnosti bolnišnic običajno uporabljamo nabor kazalnikov in kazalcev, ki bodisi v obliki odnosov med kategorijami bodisi v obliki absolutnih vrednosti izražajo poslovno uspešnost. Kazalnike poslovne uspešnosti zelo pogosto kombiniramo s kazalniki učinkovitosti, saj domnevamo, da učinkovitost vpliva na poslovno uspešnost. Glede na to, da so cene storitev $\vee$ naših bolnišnicah določene administrativno in je $\vee$ veliki meri dan tudi 
Petra Došenovič Bonča, Maks Tajnikar

Model presoje poslovne uspešnosti in izkoriščenosti

zmogljivosti v bolnišnicah

obseg delovanja posameznih bolnišnic, je $\vee$ resnici učinkovitost ključna za oblikovanje stroškov in s tem tudi za poslovno uspešnost. Vendar je uporaba takšnih kazalnikov in kazalcev sporna in pogosto ne daje resničnega vpogleda $v$ poslovno uspešnost bolnišnic, zlasti pa ne omogoča pojasnjevanja razlogov za določeno poslovno uspešnost in ne daje podlag za sprejemanje ustreznih poslovnih potez za povečanje poslovne uspešnosti. Zato $v$ tej razpravi prikazujemo, kako lahko analizo poslovne uspešnosti v bolnišnicah izboljšamo z uporabo procesnega modela in izračunov izkoriščenosti zmogljivosti znotraj posamezne bolnišnice.

\section{Pomanjkljivosti standardnih kazalnikov in kazalcev $v$ analizi poslovne uspešnosti bolnišnic}

Relativne odnose med določenimi kategorijami poslovanja običajno imenujemo kazalniki, absolutne vrednosti kategorij pa kazalci. V zdravstvu lahko opredelimo obsežen nabor kazalnikov in kazalcev, $s$ katerimi prikazujemo učinkovitost, tehnične in tehnološke značilnosti postopkov zdravljenja in opreme, uspešnost zdravljenja in uspešnost poslovanja. Poslovna poročila slovenskih bolnišnic naj bi obsegala sistematiziran spisek kazalnikov in kazalcev njihove poslovne uspešnosti in učinkovitosti.

\subsection{Standardni kazalniki in kazalci poslovne uspešnosti in učinkovitosti bolnišnic}

$V$ bolnišnicah uspešnost in učinkovitost poslovanja ocenjujejo s pomočjo treh skupin kazalnikov in kazalcev. Prvo skupino $v$ bolnišnicah imenujejo kazalniki poslovne učinkovitosti, drugo kazalniki kakovosti in tretjo kazalniki kliničnih poti. Kazalnike poslovne učinkovitosti spremljajo vse bolnišnice po predpisani enotni metodologiji, ki je opredeljena $\vee 27$. členu in Prilogi IX Področnega dogovora za bolnišnice za pogodbeno leto 2008 (2008a).

Kazalniki poslovne učinkovitosti bolnišnic so izračunani na podlagi kazalcev o realiziranem fizičnem obsegu dela bolnišnic po posameznih dejavnostih, na podlagi podatkov o številu zaposlenih po posameznih kvalifikacijskih profilih, na podlagi podatkov o obsegu razpoložljivih materialnih zmogljivosti ter na podlagi podatkov o prihodkih, ustvarjenih s plačili za opravljene storitve s strani zunanjih plačnikov (Zavod za zdravstveno zavarovanje Slovenije, druge zavarovalnice, 
Petra Došenovič Bonča, Maks Tajnikar

bolniki s plačili iz žepa), in stroških za izvajanje dejavnosti posameznih enot bolnišnice.

Kazalniki poslovne učinkovitosti vključujejo izbrane finančne kazalnike (na primer kazalnik celotne gospodarnosti, delež amortizacije $\vee$ celotnem prihodku, delež porabljenih amortizacijskih sredstev, stopnja odpisanosti opreme, dnevi vezave zalog materiala in koeficient plačilne sposobnosti), kazalnike spremljanja učinkovitosti izrabe človeških in materialnih zmogljivosti ter nekatere druge kazalnike (na primer delež stroškov za informacijsko tehnologijo $v$ celotnih prihodkih, delež stroškov za izobraževanje $v$ odhodkih in delež stroškov energije $v$ celotnih prihodkih).

V okviru kazalnikov in kazalcev spremljanja učinkovitosti izrabe človeških zmogljivosti bolnišnice spremljajo za posamezne dejavnosti število bolnikov in obseg zdravstvenih storitev na zdravnika, na medicinsko sestro in na druge člane negovalnega osebja. Izkoriščenost materialnih zmogljivosti pa bolnišnice ločeno opazujejo za razpoložljivo opremo in razpoložljive prostore. Bolnišnice tako spremljajo izkoriščenost določenih aparatur (na primer RTG aparati, računalniška tomografija in magnetna resonanca), pri čemer ločeno spremljajo uporabo aparatov za hospitalne in ambulantne bolnike, izkoriščenost operacijskih dvoran in izkoriščenost intenzivnih enot. Izkoriščenost materialnih zmogljivosti $\checkmark$ obliki prostorov pa za posamezne dejavnosti spremljajo $z$ vidika deleža prostorov, ki se uporabljajo za opravljanje dejavnosti, $v$ celotnem razpoložljivem prostoru posamezne dejavnosti ter z vidika njihove izkoriščenosti.

\subsection{Omejitve standardnih kazalnikov in kazalcev}

Vendar nabor kazalnikov in kazalcev, ki smo jih prikazali v poglavju 1.1, ni uporaben sam po sebi, saj njihova višina in velikost za določeno obdobje ali v določenem trenutku omogoča le malo analitičnih sklepov. Take sklepe lahko naredimo šele tedaj, ko posamezne kazalnike in kazalce primerjamo med sabo. Primerjamo jih lahko $v$ času in na tej podlagi sklepamo, ali se razmere izboljšujejo ali slabšajo, primerjamo pa jih lahko tudi med bolnišnicami. Za take primerjave moramo imeti podatke o drugih bolnišnicah, še boljše pa je, če imamo izbrano bolnišnico, ki lahko igra vlogo zgleda. Pa tudi če razpolagamo z informacijami o vrednosti kazalcev in kazalnikov za več obdobij in več bolnišnic, je osnovni problem ta, da poslovodstvo bolnišnic težko spremlja veliko število različnih kazalnikov in kazalcev, obstaja pa tudi večja verjetnost neustrezne interpretacije njihove medsebojne povezanosti. Tako se za primerjavo med 
Petra Došenovič Bonča, Maks Tajnikar

Model presoje poslovne uspešnosti in izkoriščenosti

zmogljivosti v bolnišnicah

enotami določene bolnišnice in med bolnišnicami uporabljajo drugačne metode primerjalne analize (na primer Ozcan, 2008, str. 3-13 ter Hollingsworth in Peacock, 2008, str. 28-42).

Da bi lahko s takimi primerjavami izvedli analitične sklepe, ki bi izkazovali resnične razmere, in zlasti da bi lahko na podlagi teh sklepov potegnili poslovne poteze, ki bi povečale poslovno uspešnost, moramo poznati medsebojno odvisnost posameznih kazalnikov in kazalcev. Pri tem pa naletimo na problem heterogenosti poslovnih procesov med različnimi bolnišnicami in celo znotraj njih, torej na primer med oddelki, klinikami ali enotami. Povečanje določenega kazalnika $\vee$ določeni bolnišnico lahko vodi do izboljšanja poslovne uspešnosti, $v$ drugi pa jo znižuje. Absolutna raven nekega kazalnika ali kazalca $\vee$ različnih bolnišnicah, enotah ali oddelkih različno vpliva na poslovno uspešnost. $\vee$ praksi vedno kaže določen kazalnik ali kazalec pri medsebojnih primerjavah razlike $v$ učinkovitosti in uspešnosti poslovanja pa tudi razlike, ki izhajajo iz heterogenosti poslovnih procesov.

Ker na poslovno uspešnost $v$ bolnišnicah vpliva tudi plačilni sistem $z$ višino cen za zdravstvene storitve in z obsegom podeljene dejavnosti znotraj zdravstvene mreže, večina kazalcev in kazalnikov poslovne uspešnosti ni ustrezna le zaradi navedenih težav pri njihovi uporabi, pač pa je neuporabna tudi zaradi vpliva plačilnega sistema na njihove denarne vrednosti. Upoštevati je treba zlasti spodbude, ki jih ustvarja plačilni sistem, oziroma vplive plačilnega sistema na obnašanje in odločitve izvajalcev zdravstvenih storitev (Kornai, Eggleston, 2001, str. 84-85; Phelps, 2002, str. 376-429). Najpomembnejši kazalniki poslovne uspešnosti so tako $v$ neki bolnišnici odvisni od cen storitev, obsega podeljene dejavnosti, plačilnega sistema, razpoložljive tehnologije in izbranih tehnik ter od stroškovne in tehnične učinkovitosti. Zavedati se moramo, da je le doseganje tehnične in stroškovne učinkovitosti v resnici v rokah poslovodstev $v$ bolnišnicah. Kazalniki uspešnosti naj bi namreč vključevali zgolj kategorije, ki so pod vplivom vodstva, nediskrecijskih dejavnikov pa ne, saj $\vee$ tem primeru dobimo neustrezno sliko poslovne uspešnosti in učinkovitosti $\vee$ primerjavah med različnimi bolnišnicami.

Da bi se izognili večini omenjenih težav pri analizi poslovanja bolnišnic in da bi znali razlikovati med različnimi dejavniki, ki vplivajo na poslovno uspešnost bolnišnic, si lahko pomagamo z analizo izkoriščenosti zmogljivosti in poslovne uspešnosti, ki temelji na uporabi prilagojenega procesnega modela bolnišnice. Analiza poslovne uspešnosti bolnišnic mora torej izhajati iz poteka poslovnih procesov bolnišnice. Pomembno vlogo pri doseganju večje učinkovitosti in 
Petra Došenovič Bonča, Maks Tajnikar

uspešnosti so izboljšavam pri izvajanju procesov pripisovali že začetniki zgodnejših teorij o menedžmentu (npr. Taylorjev znanstveni menedžment), z razvojem sistemske teorije in s prispevki sodobnih teoretikov pa je postalo jasno, da do maksimizacije učinkovitosti posameznih oddelkov in funkcij $v$ organizaciji lahko pride tudi na račun učinkovitosti in uspešnosti organizacije kot celote. Prav te vidike namreč izpostavljajo sistemska teorija, ki organizacijo obravnava kot kompleksen sistem, sestavljen iz medsebojno in z okoljem povezanih delov z določenimi lastnostmi, in prispevki sodobnih teoretikov, zlasti s formalizacijo ideje o verigi vrednosti, ki presega meje oddelkov ali funkcij podjetja ali organizacije, kar je pomembno prispevalo k razvoju procesnega pogleda na organizacije (Harmon, 2007). Analizo izkoriščenosti zmogljivosti in poslovne uspešnosti, ki temelji na uporabi procesnega modela bolnišnice, lahko izvedemo $v$ vsaki bolnišnici posebej, zanjo ni nujno, da imamo na voljo primerjalne podatke iz drugih bolnišnic, posebej pomembno pa je, da omogoča izoblikovanje določenih predlogov za prenovo procesov, ki bi pripeljali do večje učinkovitosti in uspešnosti poslovanja $v$ bolnišnici.

\section{Procesni model in presoja poslovne uspešnosti in izkoriščenosti zmogljivosti v bolnišnicah}

Procesni model, ki ga lahko uporabimo za analizo poslovne uspešnosti, mora slediti toku bolnikov, ko ti vstopajo $v$ bolnišnico, prehajajo iz ene dejavnosti oziroma enote bolnišnice $v$ drugo znotraj bolnišnice in izstopajo iz bolnišnice. Pri tem zaposlujejo zmogljivosti iz različnih klinik, oddelkov in enot znotraj in tudi zunaj bolnišnice, $v$ kolikor bolnišnica za določene storitve napoti bolnike k drugim zdravstvenim organizacijam, obremenjujejo različne človeške in materialne zmogljivosti v bolnišnici, povzročajo stroške in ustvarjajo pravice bolnišnice $v$ okviru plačilnega sistema do prihodkov bolnišnice. Tokove bolnikov med oddelki in enotami bolnišnice opredeljujejo procesi zdravstvene obravnave bolnika. Ti procesi neposredno prispevajo k ustvarjanju vrednosti bolnišnic oziroma $\mathrm{k}$ doseganju ustreznega izida zdravstvene oskrbe, zato jih imenujemo tudi temeljni poslovni procesi (Ould, 1995; Harmon, 2007; Lenz in Reichert, 2007).

Stroški pa $v$ procesu zdravstvene obravnave nastajajo tudi zaradi podpornih poslovnih procesov, zato je treba pri analizi poslovne uspešnosti temeljnih procesov upoštevati tudi stroške, ki jih povzročajo podporni procesi. 
Petra Došenovič Bonča, Maks Tajnikar

Model presoje poslovne uspešnosti in izkoriščenosti

zmogljivosti v bolnišnicah

\subsection{Dva koraka pri presoji poslovne uspešnosti in izkoriščenosti zmogljivosti}

Analiza poslovne uspešnosti, ki upošteva temeljne procese oziroma tokove bolnikov $\vee$ bolnišnici, obsega $\vee$ grobem dve fazi. $\vee$ prvi fazi oblikujemo procesno sliko bolnišnice, ki kaže tokove bolnikov znotraj bolnišnice med posameznimi oddelki in enotami, pa tudi tokove bolnikov med bolnišnico in drugimi zdravstvenimi organizacijami. Cilj te faze ni le opredeliti procese in njihovo medsebojno odvisnost, pač pa tudi kvantificirati aktivnosti, ki tečejo znotraj teh procesov. Na tej podlagi dobimo $v$ drugi fazi dva bistvena rezultata za analizo poslovanja. Prvi rezultat se navezuje na ugotovitev o izkoriščanju človeških in materialnih zmogljivosti $\vee$ posameznih procesih in dejavnostih, drugi rezultat pa se nanaša na ugotovitev o uspešnosti poslovanja po posameznih procesih, in sicer z vidika organizacijskih enot, ki sodelujejo $v$ teh procesih. Oba rezultata sta lahko podlaga za preoblikovanje procesov, ki privede do večje učinkovitosti, pa tudi do znižanja stroškov $\vee$ bolnišnici. Zlasti analiza izkoriščenosti človeških in materialnih zmogljivosti omogoča tudi organizacijske spremembe, ki vodijo do bolj izglajenega toka bolnikov skozi procese. Takšna analiza uspešnosti poslovanja daje tudi odgovor na vprašanje, v kolikšni meri so procesi, skozi katere teče tok bolnikov, obremenjeni s stroški podpornih služb, saj je opredelitev temeljnih procesov povezana tudi z opredelitvijo njihovih podpornih procesov. Poleg tega pa primerjava tako opredeljene poslovne uspešnosti določene enote $z$ izkoriščenostjo človeških in materialnih zmogljivosti te enote kaže tudi, $v$ kolikšni meri lahko vodstvo vpliva na poslovno uspešnost. Če določena enota kljub polni izkoriščenosti zmogljivosti in ustreznemu izvajanju svojih temeljnih poslovnih procesov dosega nizko poslovno uspešnost, lahko ugotovimo, da je nizka poslovna uspešnost posledica na primer neustreznega plačilnega sistema za opravljanje dejavnosti; to pa je nediskrecijski dejavnik, ki vpliva na uspešnost opazovane enote, česar pri primerjavah poslovne uspešnosti takšne enote $z$ drugimi enotami ne smemo zanemariti.

\subsection{Procesni model}

Pri oblikovanju procesnega modela bolnišnice je smiselno domnevati, da so procesi povezani s tokovi bolnikov, takšni procesi zdravstvene obravnave pa zahtevajo, da se bolniki gibljejo med posameznimi oddelki in enotami. Posamezne bolnišnice so namreč organizacijsko razdeljene na oddelke, ki izvajajo različne zdravstvene dejavnosti. Ključni dejavnosti bolnišnic sta bolnišnična 
Petra Došenovič Bonča, Maks Tajnikar

dejavnost in specialistična ambulantna dejavnost. Posamezne oddelke bolnišnične in specialistične ambulantne dejavnosti pa sestavlja več enot, ki so specializirane za izvajanje določenih specialnosti zdravstvenih dejavnosti, torej za določen nabor zdravstvenih storitev. Da bi lahko oblikovali dovolj natančen procesni model oziroma dovolj natančno strukturo procesov zdravstvene obravnave, je smiselno opazovati tokove bolnikov med enotami na čim nižji ravni opazovanja. Natančno zajemanje poteka procesov $v$ bolnišnicah z namenom ugotavljanja uspešnosti in učinkovitosti je nujno zato, ker so tokovi bolnikov oziroma procesi zdravstvene obravnave kompleksni, pri njihovi izvedbi pa sodeluje veliko ljudi z različnih področij in specialnosti. Poleg tega velja, da tudi znotraj posameznih izvajalcev ti procesi niso omejeni na posamezne oddelke ali poslovne funkcije. Ti procesi se pogosto spreminjajo zaradi tehnološkega napredka, razvoja novih metod zdravstvene obravnave ali novih postopkov, ki so povezani z obravnavo posameznega bolnika. Večine aktivnosti posameznih procesov zdravstvene obravnave ne moremo $\vee$ celoti avtomatizirati, številne aktivnosti pa niso primerne niti za delno avtomatizacijo in je njihovo izvajanje $v$ celoti vezano na zdravstveno in drugo osebje. Med procesi zdravstvene obravnave in znotraj njih poteka prenos velikega obsega in velikega števila različnih informacij, kakovost in obseg sodelovanja in usklajevanja dela med osebjem in med osebjem in opremo, tako medicinsko opremo kot sistemi za podporo odločanju, pa sta ključna pri zagotavljanju kakovostne zdravstvene oskrbe bolnikov ter pri obvladovanju stroškov zdravstvene oskrbe (Poulymenopoulou, Malamateniou in Vassilacopoulos, 2003; Anyanwu et al., 2003).

Glede na to, da moramo procese opazovati z vidika toka bolnikov, so posamezne enote bodisi začetna bodisi končna točka teh procesov, $v$ velikem številu primerov pa le mesto, na katero vstopa bolnik, a je zunaj med začetno in končno točko nekega procesa. $V$ teh primerih bolnik začasno izstopi iz procesne poti in se čez čas vrne na osnovno procesno pot. Pri tem je osnovni tok bolnikov vezan na vstop bolnikov iz okolja $\vee$ bolnišnico in izstop bolnikov iz bolnišnice $v$ okolje. Vstop bolnikov $v$ bolnišnico lahko nastane na podlagi napotitve osebnega zdravnika, na podlagi napotitve drugih izvajalcev zdravstvenega varstva pa tudi brez napotitve. Čeprav bi lahko v procesnem modelu bolnišnice domnevali, da bolniki načeloma vstopajo $v$ bolnišnico skozi enote specialistične ambulantne dejavnosti (ambulante), so lahko take vstopne točke $v$ procesnem modelu tako ambulante kot enote bolnišnične dejavnosti (bolnišnične enote). Čeprav bi lahko domnevali, da je osnovna točka izstopov bolnikov iz bolnišnice 
Petra Došenovič Bonča, Maks Tajnikar

Model presoje poslovne uspešnosti in izkoriščenosti

zmogljivosti v bolnišnicah

enota, $\vee$ kateri bolnik vstopi $\vee$ bolnišnico, $\vee$ procesnem modelu bolnišnice ni smiselno omejiti izstopa bolnikov iz bolnišnice na vstopno točko.

Ker procesni model bolnišnice oblikujemo na podlagi tokov bolnikov in ker ga uporabljamo z namenom ugotavljanja poslovne uspešnosti, je smiselno v procesnem modelu opazovati zgolj enote, ki sodelujejo pri zdravstveni obravnavi bolnikov in tako tudi ustvarjajo prihodke bolnišnice. S pomočjo procesnega modela tako ni smiselno opazovati uspešnosti enot, ki izvajajo nezdravstvene dejavnosti. Takšne enote izvajajo podporne procese temeljnih zdravstvenih procesov, zato jih je treba ustrezno povezati s temeljnimi procesi. V bolnišnicah lahko nezdravstvene dejavnosti razdelimo $v$ dve skupini. $V$ prvo sodi zdravstvena administracija, $\vee$ drugo pa ostale podporne dejavnosti (npr. računovodstvo, vzdrževanje in čiščenje). Ti dve skupini moramo $v$ procesnem modelu obravnavati različno. Dejavnost zdravstvene administracije je namreč neposredno povezana z zdravstvenimi dejavnostmi posameznih enot, zato je treba zmogljivosti in stroške zdravstvene administracije opazovati $\vee$ okviru posameznih enot, ki opravljajo zdravstvene dejavnosti. Druge nezdravstvene dejavnosti pa ne vstopajo $v$ oblikovanje procesov, znotraj katerih se gibajo bolniki, zato jih ni smiselno upoštevati pri ugotavljanju izkoriščanja človeških in materialnih zmogljivosti v bolnišnici. Treba pa je upoštevati stroške, ki nastajajo zaradi izvajanja takšnih podpornih dejavnosti, in jih mora bolnišnica pokrivati z ustvarjanjem določenega presežka prihodkov nad odhodki posameznih enot, ki izvajajo zdravstvene dejavnosti.

\subsection{Elementi procesnega modela}

Sestavni deli modela bolnišnice, ki jih prikazuje Slika 1, so:

1. enote, ki sestavljajo organizacijsko strukturo bolnišnice;

2. vstop bolnikov $v$ posamezno opazovano enoto od zunaj, torej vstop iz okolja bolnišnice;

3. vstop bolnikov $\vee$ posamezno opazovano enoto iz drugih enot bolnišnice, ki lahko nastanejo bodisi zaradi napotitve bolnika $v$ opazovano enoto na pregled ali napotitve bolnika $\vee$ opazovano enoto na nadaljnjo obravnavo;

4. razpoložljivi inputi $\vee$ obliki tako človeških kot materialnih zmogljivosti, ki jih zaposluje opazovana enota, ki izvaja zdravstveno obravnavo oziroma zdravstvene storitve; 
Petra Došenovič Bonča, Maks Tajnikar Model presoje poslovne uspešnosti in izkoriščenosti zmogljivosti v bolnišnicah

5. tehnični količniki za posamezno opazovano enoto $v$ obliki normativov uporabe tako človeških kot materialnih zmogljivosti, ki omogočajo izračun potrebnih inputov glede na enega bolnika, za katerega opazovana enota izvaja zdravstveno obravnavo oziroma zdravstvene storitve.

\subsubsection{Matrika napotitev na pregled in matrika napotitev na nadaljnjo obravnavo}

Če opazujemo obremenjenost posamezne enote znotraj bolnišnice z bolniki, obseg te obremenjenosti ne določa zgolj vstop bolnikov od zunaj $v$ bolnišnico, pač pa obseg obremenjenosti določajo tudi tokovi, ki se vzpostavljajo med enotami znotraj bolnišnice. Posamezna enota je torej lahko obremenjena z bolniki, ki vstopajo od zunaj v bolnišnico, z bolniki, ki prihajajo iz druge enote $v$ to enoto na pregled, in $z$ bolniki, ki so napoteni iz druge enote, ker so tam zaključili zdravljenje in nadaljujejo obravnavo $v$ tej enoti. $S$ posnetkom kvantitativnih vidikov teh premikov bolnikov lahko oblikujemo dve matriki procesov, ki kažeta tok bolnikov med posameznimi enotami v bolnišnici.

Prva matrika kaže tokove bolnikov $\vee$ primeru, ko bolniki odhajajo iz določene enote $v$ drugo enoto na pregled in s tem obremenijo po obsegu dela takšno drugo enoto. Da bi lahko oblikovali takšno matriko, moramo torej za vsako enoto $v$ bolnišnici ugotoviti, $v$ katere druge enote ta enota napoti svoje bolnike, opredeliti pa je treba tudi število takšnih bolnikov. Poleg tega pa je za ustrezno ugotavljanje poslovne uspešnosti takšne enote treba ugotoviti tudi, koliko bolnikov ta enota napoti na pregled $\mathrm{k}$ drugim zdravstvenim organizacijam, saj ima bolnišnica zaradi takšnih napotitev stroške.

Druga matrika pa kaže kvantitativne vidike procesov, ki nastajajo z nadaljnjo obravnavo bolnikov znotraj bolnišnice. Tudi $v$ tem primeru je treba upoštevati, da lahko bolnik zaključi obravnavo znotraj katerekoli enote bolnišnice in nadaljuje obravnavo v katerikoli drugi enoti bolnišnice. Pri matriki napotitev na nadaljnjo obravnavo lahko upoštevamo tudi, da lahko bolniki nadaljujejo obravnavo pri drugih zdravstvenih organizacijah. Ker pa takšni bolniki ne obremenjujejo niti človeških in materialnih zmogljivosti bolnišnice niti ne povzročajo stroškov tej bolnišnici, jih ni treba upoštevati pri kvantifikaciji procesnega modela bolnišnice, ki ga uporabljamo za oceno izkoriščenosti človeških in materialnih zmogljivosti ter poslovne uspešnosti njenih enot. 
Petra Došenovič Bonča, Maks Tajnikar

Model presoje poslovne uspešnosti in izkoriščenosti

zmogljivosti v bolnišnicah

\section{Slika 1: Model bolnišnice}

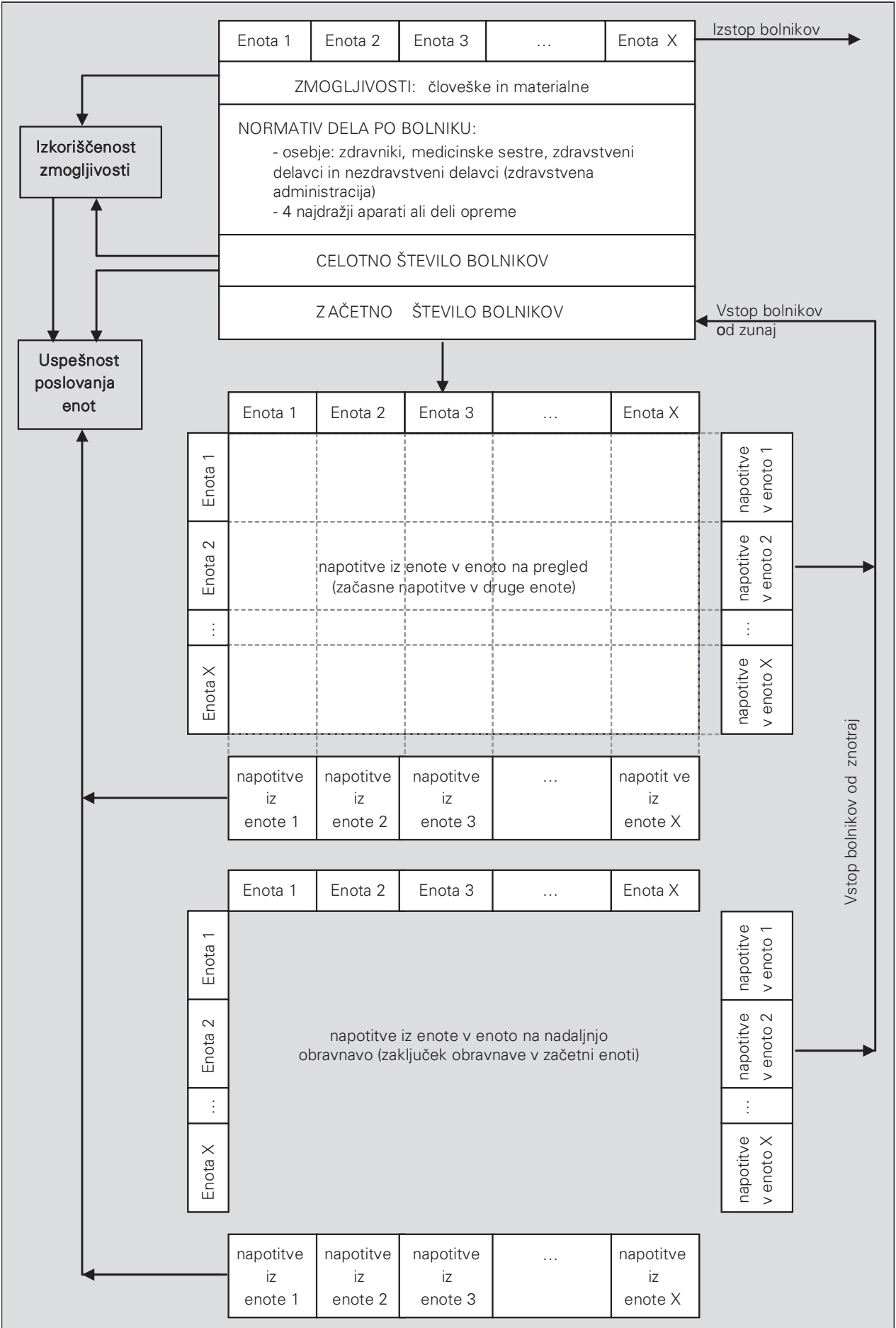


Petra Došenovič Bonča, Maks Tajnikar Model presoje poslovne uspešnosti in izkoriščenosti zmogljivosti v bolnišnicah

\subsubsection{Kvantifikacija toka bolnikov}

Bolnišnice podatkov o tokovih bolnikov med enotami, ki nastajajo bodisi zaradi napotitev na pregled bodisi zaradi napotitev $\vee$ nadaljnjo obravnavo, ne poročajo $\vee$ svojih letnih poročilih, prav tako pa jih $\vee$ takšni obliki ne zahtevajo plačniki zdravstvenih storitev. Tako je mogoče matriko napotitev na pregled in matriko napotitev na nadaljnjo obravnavo oblikovati zgolj na podlagi internih podatkov bolnišnic in razgovorov $z$ zaposlenimi $v$ posameznih enotah bolnišnice.

Pri ugotavljanju celotnega števila bolnikov, ki obremenjujejo posamezno enoto in vstopajo vanjo bodisi od zunaj bodisi iz drugih enot zaradi napotitev na pregled ali na nadaljnjo obravnavo, pa ne moremo vseh enot bolnišnic obravnavati ne enak način, saj bolnišnice ne poročajo podatkov o bolnikih in opravljenih storitvah na enak način za vse dejavnosti in posledično enote, ki te dejavnosti izvajajo.

Glede na razpoložljivost podatkov o tokovih bolnikov lahko posamezne enote razporedimo $\vee$ pet skupin glede na to, ali se na ravni enote pojavlja izvirno financiran prihodek, ki nastane z zaračunavanjem storitev plačniku zunaj bolnišnice (prihodek je na primer za specialistične ambulantne dejavnosti opredeljen s ceno in številom točk, za bolnišnične dejavnosti pa s ceno in številom uteži za posamezno skupino primerljivih primerov), in glede na zajemanje števila bolnikov, ki končajo obravnavo $\vee$ posamezni enoti (število zaključenih obravnav). Razpoložljivost podatkov o tokovih bolnikov je odvisna od mehanizmov plačevanja zdravstvenih storitev, ki so uveljavljeni v Sloveniji. Za leto 2008 na primer so ti mehanizmi in načini spremljanja podatkov o številu bolnikov in opravljenih storitvah opredeljeni v Splošnem dogovoru za pogodbeno leto 2008 (2008b), v Področnem dogovoru za bolnišnice za pogodbeno leto 2008 (2008c) in v Navodilu o beleženju in obračunavanju zdravstvenih storitev (2009).

$\checkmark$ prvo skupino lahko uvrstimo enote, pri katerih ne moremo ugotoviti niti prihodka niti števila zaključenih obravnav (na primer laboratorij). Zanje je značilno, da vanje ne vstopajo bolniki od zunaj, obravnave bolnikov znotraj takšnih enot pa nastajajo z napotitvijo bolnikov iz drugih enot bolnišnice, in sicer tako iz ambulant kot iz bolnišničnih enot.

Za drugo skupino enot je značilno, da pri njih nastaja prihodek, čeprav v bolnišnici ne ugotavljajo števila zaključenih obravnav (na primer fizioterapija za potrebe ambulant). Prihodek $v$ teh primerih nastaja $s$ financiranjem obravnav bolnikov, ki prihajajo $\vee$ takšno enoto iz ambulant bodisi na pregled bodisi na nadaljnjo obravnavo. Za obravnavo bolnikov, ki so napoteni iz bolnišničnih enot, 
Petra Došenovič Bonča, Maks Tajnikar

Model presoje poslovne uspešnosti in izkoriščenosti

zmogljivosti v bolnišnicah

pa takšne enote ne dobijo plačila od zunanjega plačnika, saj je celotna obravnava takšnih bolnikov financirana $\vee$ okviru sistema plačila skupin primerljivih primerov. Za enote druge skupine je značilno tudi, da vanje ne vstopajo bolniki od zunaj, saj bi bili sicer zabeleženi v okviru števila zaključenih obravnav.

Za tretjo skupino enot je značilno, da pri njih ni mogoče ugotoviti prihodka, obstaja pa število zaključenih obravnav znotraj enote. $V$ tem primeru število zaključenih obravnav obsega tako zaključene obravnave bolnikov, ki prihajajo od zunaj, s čimer ustvarja enota tržni prihodek, kot bolnike, ki prihajajo $v$ enoto iz te skupine iz ambulant na pregled. Ne zajema pa bolnikov, ki prihajajo iz bolnišničnih enot na pregled $v$ takšno enoto, saj so ti zajeti že $v$ okviru financiranja skupin primerljivih primerov, niti bolnikov, ki prihajajo iz ambulant in bolnišničnih enot na nadaljnjo obravnavo, saj domnevamo, da v takšnih enotah ne teče nadaljnja obravnava.

$\checkmark$ četrti skupini, ki zajema bolnišnične enote, za katere je značilno, da lahko ugotovimo tako prihodek kot število zaključenih obravnav (število odpuščenih bolnikov) na ravni enote, pa število zaključenih obravnav obsega poleg bolnikov, ki vstopajo $v$ bolnišnico od zunaj, tudi bolnike, ki vstopajo iz ambulant na nadaljnjo obravnavo. $\vee$ primerih, ko vstopajo $v$ takšno bolnišnično enoto na nadaljnjo obravnavo bolniki iz ambulant znotraj bolnišnice, se namreč $\vee$ obravnavani bolnišnični enoti odpirajo novi primeri iz skupin primerljivih primerov. Tok bolnikov iz ambulant zgolj na pregled $v$ bolnišnično enoto pa znotraj bolnišnice zaradi narave bolnišničnih enot ne nastaja in zato tudi ni vključen $v$ število zaključenih obravnav znotraj bolnišničnih enot. Vstop bolnikov $\vee$ določeno enoto bolnišnične dejavnosti iz drugih enot bolnišnične dejavnosti na pregled (na primer konziliarni pregledi) pa tudi ni zajet $v$ številu zaključenih obravnav, saj mora bolnišnica strošek takšnih storitev kriti s plačili za skupine primerljivih primerov tistih enot, ki so napotile bolnika na pregled.

Za peto skupino enot, ki zajema ambulante, $v$ kateri bolnišnica izkazuje tako prihodek kot število zaključenih obravnav (število obiskov) znotraj enote, je značilno, da število zaključenih obravnav obsega poleg bolnikov, ki vstopajo $v$ enoto od zunaj, tudi bolnike, ki so napoteni iz drugih ambulant $v$ analizirano ambulanto zaradi pregleda ali nadaljnje obravnave, pa tudi bolnike, ki vstopajo iz bolnišničnih enot $v$ nadaljnjo obravnavo $v$ analizirano ambulanto. Ne zajema pa bolnikov, ki prihajajo iz bolnišničnih enot $v$ posamezno ambulanto zgolj na pregled, saj so ti bolniki plačani $\vee$ okviru sistema financiranja skupin primerljivih primerov in niso posebej plačani v okviru dejavnosti analizirane ambulante. 
Petra Došenovič Bonča, Maks Tajnikar

\subsubsection{Celotno število bolnikov v določeni enoti}

Glede na opisano kompleksnost tokov bolnikov med enotami bolnišnice in ugotavljanja števila bolnikov, ki jih obravnavajo $v$ posamezni enoti, in glede na cilj procesnega modela, moramo vpeljati $\vee$ model klasifikacijo posameznih enot $\checkmark$ omenjenih pet skupin. Ker je število bolnikov, ki obremenjuje posamezno enoto, seštevek števila bolnikov, ki vstopajo od zunaj, in števila bolnikov, ki vstopajo $v$ enoto iz drugih enot na pregled ali nadaljnjo obravnavo, in ker $v$ bolnišnici ne spremljajo števila bolnikov, ki vstopajo od zunaj, pač pa število zaključenih obravnav, moramo $v$ modelu za vsako od petih skupin enot izračunati število bolnikov, ki vstopajo od zunaj iz števila zaključenih obravnav. Takšna korekcija je potrebna, saj z opredelitvijo procesov ugotovimo število bolnikov, ki v enoto vstopa zaradi napotitve na pregled ali nadaljnjo obravnavo. Če bi to število bolnikov zgolj prišteli k številu zaključenih obravnav, bi zaradi dvojnega štetja nekaterih skupin bolnikov $v$ modelu izkazovali nerealne obremenitve posameznih enot bolnišnice.

Z upoštevanjem števila bolnikov, ki vstopajo $v$ določeno iz drugih enot bolnišnice, in števila bolnikov, ki vstopajo od zunaj, kar smo izračunali iz števila zaključenih obravnav, lahko ugotovimo celotno število bolnikov, ki obremenjujejo posamezno enoto. To število kaže neto obremenitev posamezne enote z bolniki, ki bodisi prihajajo $v$ bolnišnico in enoto od zunaj in $v$ enoto $z$ napotitvami znotraj bolnišnice na pregled ali v nadaljnjo obravnavo.

\subsubsection{Normativi uporabe zmogljivosti določene enote na bolnika}

Za opredelitev povpraševanja po človeških in materialnih zmogljivostih $v$ bolnišnici je treba število bolnikov, ki izhaja iz njihovih tokov $\vee$ bolnišnici, spremeniti $\vee$ povpraševanje po posameznem tipu zmogljivosti. Za ta namen opredelimo, koliko delovnih ur ali koliko strojnih ur potrebuje posamezni bolnik $\checkmark$ povprečju znotraj posamezne enote $\vee$ delovnem procesu, $\vee$ katerega je vključen pri svojem zdravljenju. Zaradi tega je treba $\vee$ procesni model bolnišnice vključiti nabor normativov uporabe za vsak tip zmogljivosti in za vsako enoto opazovanja v bolnikovem toku posebej. Normativi kažejo intenzivnost zaposlitve posameznega elementa zmogljivosti, pri čemer je $v$ primeru bolnišnic smiselno, da upoštevamo človeške, prostorske in posteljne zmogljivosti ter zmogljivost aparatov.

Zaposlenost človeških zmogljivosti oziroma delovne sile lahko ugotavljamo s časovnim obsegom dela, izmerjenega $\vee$ urah, katerega posamezni kvalifikacijski profil potroši za obravnavo posameznega bolnika $\vee$ celotnem času, ki ga 
Petra Došenovič Bonča, Maks Tajnikar

Model presoje poslovne uspešnosti in izkoriščenosti

zmogljivosti v bolnišnicah

posamezni bolnik prebije $\vee$ obravnavi znotraj posameznega oddelka. Pri velikosti prostorov oziroma površin, ki pripadajo posamezni enoti, moramo opredeliti potrebno velikost glede na značilnosti dejavnosti, ki se $v$ teh prostorih izvajajo, in glede na število bolnikov, kar lahko za posamezno bolnišnico ocenimo na podlagi preteklih podatkov, primerjave z drugimi bolnišnicami ali glede na ekspertno mnenje. Pri ugotavljanju posteljnih zmogljivosti lahko izhajamo iz povprečne ležalne dobe, ki je značilna za določeno enoto bolnišnice. Pri aparatih pa lahko izhajamo iz časovnih normativov, izraženih v urah, ki kažejo, koliko časa posamezni bolnik $v$ celotnem obdobju svoje obravnave znotraj ene enote zaseda neki aparat.

Vsi navedeni normativi (normativi za delovno silo, prostor, posteljne zmogljivosti in aparate) so $v$ modelu konstantni in jih zato razumemo kot tehnične normative.

\section{Presoja izkoriščenosti zmogljivosti}

Analiza izkoriščenosti človeških in materialnih zmogljivosti je $\vee$ bistvu stranski proizvod na poti k analizi poslovne uspešnosti bolnišnice. Ker pa je del iste analize, seveda razkriva tudi pomembne dejavnike, ki vplivajo na njeno poslovno uspešnost. $V$ bistvu je naturalni vidik poslovne uspešnosti bolnišnice, čeprav izkoriščenost zmogljivosti ne pomeni nujno tudi tehnične in stroškovne učinkovitosti bolnišnice. Neka bolnišnica je namreč lahko tehnično neučinkovita, kar pomeni, da na enoto outputa uporablja prevelik obseg inputov $\checkmark$ primerjavi z učinkovitimi bolnišnicami, a te inpute polno zaposluje. Za analizo izkoriščenosti zmogljivosti po enotah bolnišnice potrebujemo povpraševanje po teh zmogljivostih, ki ga dobimo iz toka bolnikov in normativov uporabe zmogljivosti na bolnika, in obseg zmogljivosti po enotah.

\subsection{Potrebe po zmogljivostih $v$ enotah}

Pri delovni sili lahko povpraševanje opredelimo na osnovi normativov, ki kažejo obravnavo posameznega bolnika znotraj celotne obravnave $v$ eni enoti $v$ urah, in števila bolnikov, ki jih obravnavajo $v$ enem letu znotraj posamezne enote. Glede na to, da smo pri normativih za delovno silo opredelili čas, ki ga posamezni zdravstveni delavec nameni obravnavi posameznega bolnika $\vee$ 
Petra Došenovič Bonča, Maks Tajnikar Model presoje poslovne uspešnosti in izkoriščenosti zmogljivosti v bolnišnicah

smislu dnevnega normativa, je treba pri izračunavanju povpraševanja po človeških zmogljivostih znotraj posamezne enote upoštevali tudi ležalno dobo bolnikov $\vee$ okviru enote. $\vee$ primerih, ko statistika $v$ bolnišnicah ne zajema teh ležalnih dob (na primer za ambulante), pa je smiselno domnevati, da je dnevni normativ ustrezen. Takšno povpraševanje je odvisno torej od števila bolnikov in od normativov za obravnavo posameznega bolnika $v$ času, ki ga bolnik preživi znotraj posamezne enote.

Tudi povpraševanje po prostoru in po posteljah moramo opredeliti na osnovi števila bolnikov. Potreben prostor pa lahko določimo z upoštevanjem normativa potrebnega prostora na bolnika in števila bolnikov, ki vstopajo $v$ posamezno enoto. Povpraševanje po posteljnih kapacitetah pa lahko opredelimo na podlagi števila bolnikov in povprečne ležalne dobe $v$ posamezni enoti. Tudi povpraševanje po posameznih aparatih je povezano s številom bolnikov, ki vstopajo $v$ posamezno enoto, $z$ deležem teh bolnikov, ki so obravnavani $s$ pomočjo posameznega aparata, in s časovnim normativom, izraženim $v$ urah, za obravnavo pacienta na takšnem aparatu.

\subsection{Razpoložljive zmogljivosti po enotah}

Dejavnosti, ki se izvajajo $v$ posameznih enotah, moramo opazovati tudi z vidika zmogljivosti, ki jih posamezna enota uporablja pri izvajanju teh dejavnosti.

Človeške zmogljivosti lahko opazujemo z vidika štirih tipičnih kvalifikacijskih profilov, ki delujejo znotraj posamezne enote. Delovno silo bolnišnic lahko zajamemo v kategorijah zdravnikov, medicinskih sester, drugih zdravstvenih delavcev in nezdravstvenih delavcev. Pri vseh štirih profilih je potrebno ugotoviti število zaposlenih $v$ posamezni kategoriji, pri tem pa zaradi medsebojne odvisnosti enot upoštevati tudi dejstvo, da nekateri zaposleni delujejo $v$ različnih enotah.

Materialne zmogljivosti pa moramo opazovati z vidika površine prostorov, ki jih za svojo dejavnost uporablja posamezna enota, z vidika števila bolniških postelj in števila različnih vrst aparatov, ki jih uporablja enota pri izvajanju svoje dejavnosti. Glede na to, da v bolnišnicah uporabljajo veliko različnih aparatov in opreme, se je z vidika ugotavljanja uspešnosti smiselno omejiti zgolj na najdražje tipe aparatov in tako omejiti nabor aparatov, za katere ugotavljamo stopnjo izkoriščenosti. Pri opredelitvi vrednosti aparatov je smiselno upoštevati njihovo nabavno vrednost in oblikovati ključe za delitev stroškov amortizacije ob predpostavki, da doba uporabe vseh ključnih aparatov ne presega amortizacijske 
Petra Došenovič Bonča, Maks Tajnikar

Model presoje poslovne uspešnosti in izkoriščenosti

zmogljivosti v bolnišnicah

dobe. Na ta način se pri analizi poslovne uspešnosti izognemo vplivu odpisanosti aparatov in opreme na poslovni izid.

\subsection{Ugotavljanje izkoriščenosti zmogljivosti enot}

Odnos med ponudbo zmogljivosti in povpraševanjem po zmogljivostih kaže izkoriščenost človeških in materialnih zmogljivosti znotraj posamezne enote. Prednost uporabe procesnega modela pri ugotavljanju izkoriščenosti zmogljivosti je opredelitev povpraševanja, ki z upoštevanjem tokov bolnikov med enotami odraža dejansko obremenitev posamezne enote.

Pravilnost ocene izkoriščenosti v največji meri izhaja iz ocene normativov zaposlovanja posameznih zmogljivosti, ki merijo intenzivnost njihove uporabe. Če je ocena normativov objektivna, lahko iz stopnje izkoriščenosti posamezne zmogljivosti izvedemo tudi sklep o stopnji njene izkoriščenosti. V primeru nizke stopnje izkoriščenosti, tedaj je nižja od 1, taka zmogljivost pomembno prispeva k stroškom, čeprav z vidika bolnišničnih procesov ni $v$ celoti potrebna. S tem lahko identificiramo zmogljivosti, ki jih lahko odpustimo ali dezinvestiramo, ali pa zanje najdemo zaposlitev $\vee$ dejavnosti zunaj bolnišnice ali $\vee$ diverzifikaciji dejavnosti same bolnišnice. $\vee$ primeru visoke stopnje izkoriščenosti zmogljivosti, ko je stopnja višja od 1, pa kaže na ozka grla, ki onemogočajo doseganje ustreznega obsega dejavnosti $v$ drugih enotah in gladek tok bolnikov med enotami. S tem lahko ugotavljamo tudi izvore čakalnih dob v bolnišnici. Pri tem dobimo tudi informacijo, ali je mogoče z večanjem intenzivnosti dela, ki se kaže $v$ normativih, doseči večji obseg dejavnosti brez zaposlovanja dodatnih zmogljivosti. Rezultat tako omogoča oceno intenzivnosti zaposlitve posameznega elementa zmogljivosti $\vee$ bolnišnici in ugotovitev morebitnih presežnih ali manjkajočih zmogljivosti. Vse to omogoča argumentacijo ključnih poslovnih potez, kot so nakup nove opreme ali zaposlitev novih delavcev, ugotovitev presežne delovne sile in nepotrebne opreme, reorganizacijo bolnišnic za bolj tekoč tok bolnikov, ko ne nastajajo čakalne vrste, in ugotavljanje zmogljivosti, ki povzročajo stroške, ne pa tudi prihodkov. Sploh ni drugega načina ugotavljanja presežne delovne sile. Analiza normativov oziroma intenzivnosti dela posameznikov pa omogoča tudi opredelitev ustreznega sistema nagrajevanja. 
Petra Došenovič Bonča, Maks Tajnikar

Model presoje poslovne uspešnosti in izkoriščenosti zmogljivosti v bolnišnicah

\section{Presoja poslovne uspešnosti bolnišnice}

Poslovno uspešnost posameznih enot ugotavljamo z izkazi uspeha, katere sestavljajo prihodki in odhodki, ki so neposredno povezani z dejavnostjo posamezne enote. Do njih pridemo tako, da $v$ procesni model in model za ugotavljanje izkoriščenosti zmogljivosti vpeljemo cene dejavnikov in storitev, ki jih opravljajo v posamezni enoti.

\subsection{Ugotavljanje odhodkov enot}

Odhodkovni del izkazov uspeha posamezne enote bolnišnice sestavljajo materialni stroški zdravil, stroški zdravstvenih storitev, stroški dela, odhodki financiranja, izredni odhodki, amortizacija in drugi stroški.

Pri tem so ključni materialni stroški zdravil, ki so izračunani iz povprečnih stroškov zdravil oziroma stroškov zdravil na bolnika $\vee$ posamezni enoti, pomnoženimi s številom bolnikov, ki so bili obravnavani v posamezni enoti. Na podoben način so izračunani tudi stroški zdravstvenih storitev, ki so načeloma izračunani $v$ odnosu do števila bolnikov, ki jih napoti posamezna enota na obravnavo k drugi zdravstveni organizaciji. Pri tem je osnovni izračun stroškov zdravstvenih storitev preprost produkt povprečne vrednosti storitev na bolnika, ki ga obravnavajo zunanji izvajalci, in števila takšnih bolnikov.

Pri opredelitvi stroškov dela posamezne enote je treba upoštevati, da lahko zaposleni delo opravljajo $v$ različnih enotah. Stroške dela tako izračunamo kot produkt števila zaposlenih iz delovnih ur po posameznih kvalifikacijskih skupinah, pri čemer upoštevamo samo delovne ure, ki jih zaposleni opravijo $v$ analizirani enoti, in dejanske stroške dela takšnih zaposlenih, vendar samo za tisti del delovnih ur, ki jih zaposleni opravijo $v$ enoti. Na ta način smo $v$ model stroške dela vključili v obliki variabilnih stroškov.

Izredne odhodke in druge stroške, ki sestavljajo odhodke posamezne enote, moramo razdeliti na enote $z$ uporabo ključev. Izredne odhodke lahko med enote delimo sorazmerno glede na materialne stroške zdravil, stroške zdravstvenih storitev, stroške dela in odhodke financiranja. Pri razporeditvi drugih stroškov pa lahko sorazmernost opredelimo glede na materialne stroške zdravil, stroške zdravstvenih storitev, stroške dela, odhodke financiranja in izredne odhodke. 
Petra Došenovič Bonča, Maks Tajnikar

Model presoje poslovne uspešnosti in izkoriščenosti

zmogljivosti v bolnišnicah

Stroške amortizacije na ravni enot izračunamo na osnovi dejanskih amortizacijskih stopenj bolnišnice in neodpisane vrednosti zgradb, neodpisane vrednosti opreme ter drugih opredmetenih osnovnih sredstev, pri čemer moramo neodpisano vrednost sredstev razporediti med enote. Neodpisano vrednost zgradb lahko razdelimo med posamezne enote glede na površino prostora, s katerim enota razpolaga, $\vee$ celotnem razpoložljivem prostoru bolnišnice. Neodpisano vrednost opreme in drugih opredmetenih osnovnih sredstev pa je smiselno razporediti na posamezno enoto glede na vrednost izbranega nabora najdražjih tipov aparatov, ki jih uporablja posamezna enota. Na ta način, kot smo pojasnili, zagotovimo, da razlike $v$ stopnjah odpisanosti opreme ne vplivajo na poslovni izid.

Med posamezne enote moramo razporediti tudi splošne stroške bolnišnice, to so stroški podpornih procesov, med katere lahko uvrstimo stroške dela uprave, službe vzdrževanja in drugih podpornih služb. Stroške dela uprave lahko med posamezne enote razporedimo glede na število bolnikov in število zaposlenih v posamezni enoti. Stroške dela služb vzdrževanja, ki zajemajo, na primer, stroške dela tehnično-vzdrževalne službe in stroške dela čistilnega servisa, lahko razporedimo glede na osnovna sredstva, s katerimi razpolaga posamezna enota.

Prav tako moramo vsako posamezno enoto obremeniti z materialnimi stroški in stroški storitev, ki niso materialni stroški zdravil in stroški zdravstvenih storitev. Nerazporejene materialne stroške lahko med enote razporedimo glede na obseg osnovnih sredstev, nerazporejene stroške storitev pa glede na število bolnikov, obravnavanih $\vee$ posamezni enoti.

Tako ugotovljene režijske stroške, ki jih posamezna enota mora pokrivati iz svojega pokritja in ki zajemajo stroške dela služb uprave, stroške dela služb vzdrževanja ter nerazporejene materialne stroške in stroške storitev uporabimo za ugotavljanje neto poslovnega rezultata posamezne enote znotraj analizirane bolnišnice. Razliko med prihodki in odhodki, ki na ravni posamezne enote nastanejo neposredno zaradi opravljanja zdravstvenih dejavnosti, smo namreč zmanjšali za te režijske stroške in tako ugotovili neto poslovni rezultat posamezne enote. S pomočjo tako opredeljenega izkaza uspeha posamezne enote lahko ugotovimo, $v$ kakšni meri posamezna enota prispeva $k$ ustvarjanju prihodka, v kakšni meri prispeva k nastajanju odhodkov, pa tudi v kolikšni meri s svojim presežkom prihodkov nad odhodki lahko pokriva splošne oziroma režijske stroške poslovanja bolnišnice. 
Petra Došenovič Bonča, Maks Tajnikar

\subsection{Ugotavljanje prihodkov enot}

Z vidika ugotavljanja poslovne uspešnosti posameznih enot je ključno ugotavljanje prihodka posamezne enote. $V$ analizi poslovne uspešnosti lahko uporabimo tri načine ugotavljanja prihodkov enote. Prvič, uporabimo lahko dejanske prihodke, ki jih plača zunanji plačnik. Drugič, dejanske prihodke pa lahko tudi popravimo z upoštevanjem vstopa bolnikov iz drugih enot, kar vključuje interno zaračunavanje določene enote za opravljene storitve drugim enotam. Tretjič, dejanske prihodke enot lahko popravimo z upoštevanjem zaračunavanja za opravljene storitve drugim enotam, pa tudi z upoštevanjem, da analizirana enota s svojimi bolniki obremenjuje druge enote in mora posledično določen del svojega prihodka prenesti na takšne druge enote. Izhodiščni prihodki iz poslovanja, ki jih uporabljamo $v$ analizi uspešnosti enot, so dejanski prihodki, ki jih posamezne enote dobijo s plačilom storitev od zunanjega plačnika.

Drugi tip prihodkov iz poslovanja izračunamo tako, da upoštevamo tako tiste bolnike, ki vstopajo iz okolice $v$ bolnišnico in jih plačuje zunanji plačnik, kot tiste bolnike, ki prihajajo iz ene enote $v$ drugo enoto znotraj bolnišnice. Pri izračunu drugega tipa prihodkov iz poslovanja izhajamo iz izhodiščnih prihodkov iz poslovanja, torej dejansko realiziranih prihodkov. Drugi tip prihodkov iz poslovanja sestavljajo prihodki, ki jih dobi enota z zaračunanjem storitev plačniku zunaj bolnišnice, in prihodki, ki bi jih enota dobila, če bi zaračunavala svoje storitve tudi enotam znotraj bolnišnice, če storitev ne plača plačnik zunaj bolnišnice. Prihodki iz poslovanja, katere izračunamo na ta način, bi morali biti enaki ali večji od prihodkov iz poslovanja, ki jih enote ustvarjajo s sistemom financiranja s strani zunanjih plačnikov njihovih storitev.

Prihodke iz poslovanja, ki upoštevajo vstop iz drugih enot, izračunamo kot produkt celotnega števila obravnavanih bolnikov, torej celotnega števila bolnikov, ki obremenjujejo enoto, in povprečnih prihodkov na bolnika, ki jih bolnišnica doseže $v$ posamezni enoti. Prihodek bolnišnica ustvarja $z$ zaračunavanjem opravljenih storitev zunanjemu plačniku, pri čemer je cena storitev oziroma cena obračunske enote, s katero se spremlja obseg storitev (točka ali utež), za bolnišnico dana kategorija. Za izračun prihodka na bolnika pa je treba ustvarjene prihodke deliti s številom bolnikov, ki jih financirajo zunanji plačniki. Kot smo pojasnili, takšno število bolnikov odraža število zaključenih obravnav.

Vendar je mogoče prihodke na bolnika na opisani način ugotoviti zgolj za četrto in peto skupino enot iz drugega poglavja tega članka, pri katerih se na 
Petra Došenovič Bonča, Maks Tajnikar

Model presoje poslovne uspešnosti in izkoriščenosti

zmogljivosti v bolnišnicah

ravni enote pojavljajo tako prihodki iz poslovanja kakor število zaključenih obravnav. V drugi skupini enot, pri kateri ne beležijo števila zaključenih obravnav na enoti, izkazujejo pa prihodke iz poslovanja, moramo prihodke na bolnika oziroma ceno obravnave posameznega bolnika izračunati nekoliko drugače, in sicer $v$ obliki količnika med prihodki iz poslovanja in celotnim številom bolnikov, ki jih obravnavajo znotraj takšne enote in ki lahko izvirajo zgolj iz napotitev na pregled ali nadaljnjo obravnavo. Pri tretji in prvi skupini enot, ki ne beležijo prihodkov iz poslovanja, pa kot ceno obravnave posameznega bolnika upoštevamo lastno ceno dejavnosti takšne enote $\vee$ obliki razmerja med celotnimi odhodkov poslovanja enoto in celotnega števila obravnavanih bolnikov.

Če bi med enotami znotraj bolnišnice obstajali tržni odnosi, bi morala enota, ki je sprejela bolnika, zaračunati svojo storitev enoti, ki je poslala bolnika, če enota prejemnica dodatne obravnave bolnika take obravnave ni dobila plačane od zunanjega plačnika. S tem bi nastali pri enoti, ki pošilja bolnike, stroški, ki bi bili podobnega značaja, kot so stroški zunanjih zdravstvenih storitev za posamezno enoto, ti stroški pa bi zmanjševali poslovno uspešnost enot, ki pošiljajo bolnike $\vee$ druge enote. Da bi ugotovili resnično uspešnost poslovanja v posamezni enoti, moramo torej poleg stroškov obravnave dejanskega števila bolnikov in prihodkov na podlagi tega števila obravnavanih bolnikov, upoštevati tudi stroške, ki bi nastali, če bi morala enota za svoje bolnike, ki jih napoti $v$ druge enote na pregled, plačati tem enotam za opravljene storitve. Če upoštevamo na opisani način tudi medsebojno zaračunavanje storitev med enotami znotraj bolnišnice, kadar storitve $v$ neki enoti, ki nastanejo s pošiljanjem pacientov iz druge enote, niso plačane s sredstvi zunanjega plačnika, dobimo poslovni rezultat posamezne enote, ki natančno izraža uspešnost take enote tudi ob upoštevanju medsebojne soodvisnosti. Prihodki v tem primeru izražajo tudi prihodke, ki nastanejo zaradi tokov znotraj enot $v$ bolnišnici in so seveda lahko enaki ali večji od prihodkov, ki jih posamezne enote dobijo od zunanjega plačnika za opravljene storitve, stroški pa $v$ tem primeru obsegajo stroške obravnave dejanskega števila bolnikov, ki vstopajo $v$ enoto, pa tudi stroške, ki jih takšna enota povzroča s pošiljanjem bolnikov na pregled ali nadaljnjo obravnavo $\vee$ drugo enoto, če teh stroškov ne pokrivajo zunanji plačniki $\vee$ drugi enoti.

\subsection{Ugotavljanje poslovne uspešnosti}

Trije poslovni rezultati v bolnišnici že sami po sebi nudijo veliko analitično podlago. Govorijo namreč, $v$ kolikšni meri zunanji plačnik $\vee$ resnici pokrije stroške neke enote, $v$ kolikšni meri bi se poslovni rezultat izboljšal, če bi z 
Petra Došenovič Bonča, Maks Tajnikar

internim fakturiranjem določena enota svoje storitve, ki jih ne dobi plačanih od zunaj, zaračunavala drugim enotam, in kakšen bi bil poslovni rezultat, če bi upoštevali $\vee$ celoti medsebojno fakturiranje storitev $v$ bolnišnici. Šele zadnji poslovni rezultat, ki ga sedaj $\vee$ nobeni bolnišnici računovodsko ne ugotavljajo, je resnična slika poslovne uspešnosti posamezne enote.

Analiza prihodkovne in odhodkovne strani izkazov uspeha po enotah odkriva tudi tiste elemente zlasti odhodkov enote, ki najbolj vplivajo na njeno poslovno uspešnost. $\mathrm{S}$ tem vidimo tudi, na kašen način lahko uvedemo stroškovne prihranke. Ker ti lahko nastanejo bodisi s spreminjanjem cene dejavnikov bodisi s spreminjanjem zaposlenih zmogljivosti, lahko z analizo izkoriščanja zmogljivosti ugotovimo, ali je mogoče s spreminjanjem zaposlenih zmogljivosti znižati stroške in izboljšati poslovni rezultat. Prav tako je mogoče oceniti, ali bi lahko z zniževanjem cen dejavnikov (na primer nižanjem cen zdravil ali povprečnih plač zaposlenih) povečali poslovno uspešnost. Poslovne cilje na področju poslovne uspešnosti lahko tako prevedemo $v$ cilje na področju gospodarjenja z zmogljivostmi. Odpravljanje presežnih zmogljivosti pa lahko prevedemo $\vee$ rezultate $\vee$ poslovni uspešnosti. Izračunamo lahko tudi, koliko bolnišnico stane odpravljanje čakalnih vrst. Posebni vidik uporabe tega modela je tudi ocena ustreznosti plačilnega sistema. Če $v$ bolnišnici ugotovijo, da ni mogoče povečati intenzivnosti in izkoriščanja zmogljivosti in da ni mogoče znižati cen dejavnikov, ob tem pa še vedno dosegajo negativni poslovni rezultat, lahko sklepajo, da je financiranje bolnišnične dejavnosti napačno. Ker analiza izkoriščenosti zmogljivosti temelji na količinskih normativih in ker se ti neposredno izražajo $v$ poslovnem uspehu, lahko vsaka bolnišnica presodi, $v$ koliki meri ji ustrezajo cene storitev, ki jih plačuje zunanji plačnik. Zato je mogoče z modelom preverjati tudi ustreznost določitve cen obračunskih enot za opravljene storitve (na primer utež $\vee$ primeru skupin primerljivih primerov, točka ali bolnišnično oskrbni dan) v okviru plačilnega sistema pri nas.

\section{Ugotovitve in priporočila}

Prikazana analiza poslovne uspešnosti v bolnišnicah z uporabo procesnega modela omogoča, da opredelimo notranje in zunanje vzroke poslovne neuspešnosti. Opredelimo lahko dva notranja vzroka. Prvi notranji vzrok poslovne neuspešnosti so neustrezni normativi, ki jih dosegajo zaposleni pri izvajanju dejavnosti na ravni posameznih enot bolnišnice. Zaradi njih obravnava 
Petra Došenovič Bonča, Maks Tajnikar

Model presoje poslovne uspešnosti in izkoriščenosti

zmogljivosti v bolnišnicah

bolnikov zahteva prevelik obseg človeških in materialnih zmogljivosti in pretirano vključevanje drugih enot bolnišnice pri izvajanju dejavnosti določene enote. Oboje tudi nepotrebno povečuje stroške izvajanja dejavnosti posamezne enote. Drugi notranji vzrok poslovne neuspešnosti pa je neustrezna izkoriščenost razpoložljivih zmogljivosti. Ta nastane, ker so razpoložljive zmogljivosti prevelike glede na obseg toka bolnikov, na normative za izvajanje dejavnosti in na medsebojno odvisnost enot v bolnišnici. Presežne zmogljivosti povzročajo nastajanje stroškov, ki so nepotrebni z vidika obsega dejavnosti, ki ga izvajajo v bolnišnicah. Če so za določeno organizacijsko enoto ustrezni tako normativi za opravljanje dejavnosti kot vključevanje drugih enot in $\vee$ njej ne nastajajo presežne zmogljivosti, poslovni uspeh enote pa je še vedno negativen, je očitno vzrok takega poslovnega neuspeha $v$ neustreznih cenah storitev, ki jih priznava zunanji plačnik. Neustrezni plačilni sistem oziroma neustrezne cene, ki jih zunanji plačnik priznava za zdravstvene storitve, je tako zunanji vzrok poslovne neuspešnosti.

Da bi vodstvo bolnišnic prikazani procesni model lahko uporabilo za presojo poslovne uspešnosti in opredelitev razlogov za nizko poslovno uspešnost na ravni posameznih enot, je treba $v$ bolnišnici spremljanje podatkov o obsegu opravljene dejavnosti in o nastalih stroških prilagoditi na način, da bodo ustrezali potrebnim vhodnim podatkom prikazanega procesnega modela. Tako je treba na ravni enot spremljati obseg opravljene dejavnosti, in sicer ne zgolj na način, kot ga zahteva zunanji plačnik zdravstvenih storitev, pač pa na način, ki omogoča opredelitev vrste vstopa bolnikov $v$ posamezno organizacijsko enoto (vstop od zunaj ali vstop iz drugih enot). Tovrstni podatki namreč omogočajo, da se na ravni posameznih organizacijskih enot opredelijo tako dejanski prihodki, ki nastanejo s plačilom zunanjega plačnika, kot transferni prihodki, ki nastanejo z zaračunavanjem storitev med posameznimi enotami. Natančno spremljanje tokov bolnikov med enotami tako omogoča tudi razporejanje nastalih stroškov med organizacijske enote bolnišnice. Za ustrezno razporejanje nastalih stroškov med organizacijske enote bolnišnice je treba na ravni enot natančno opredeliti tudi razpoložljive zmogljivosti. To je ključno tudi za izračun njihove izkoriščenosti. Primerjava razpoložljivih zmogljivosti $\mathrm{s}$ povpraševanjem po zmogljivostih, ki je določeno z normativi, ki jih dosegajo zaposleni pri opravljanju dejavnosti, in s številom obravnavnih bolnikov namreč kaže doseženo stopnjo izkoriščenosti.

Ključno za zaokrožitev opisanega procesnega modela pa je oblikovanje normativov, ki bi jih morali dosegati zaposleni pri opravljanju dejavnosti in uporabi 
Petra Došenovič Bonča, Maks Tajnikar Model presoje poslovne uspešnosti in izkoriščenosti zmogljivosti v bolnišnicah

materialnih zmogljivosti. Prav s spreminjanjem teh normativov lahko vodstvo spremlja in regulira intenzivnost in produktivnost dela ter izkoriščenost zmogljivosti ter s tem vpliva na poslovni izid enot in bolnišnice kot celote. Ti normativi so lahko tudi podlaga za uveljavitev sistema evidentiranja dejanskega dela, preko katerega lahko vodstvo spremlja obseg opravljenega dela zaposlenih, odpravi velika nesorazmerja $\vee$ obremenitvi med zaposlenimi, poleg tega pa z normativi za opravljanje dejavnosti in s sistemom evidentiranja dela stimulira zaposlene $\mathrm{k}$ učinkovitemu delu, vpliva pa lahko tudi na strukturo ponudbe bolnišnice.

Mag. Petra Došenovič Bonča je asistentka na Katedri za ekonomsko teorijo in politiko na Ekonomski fakulteti Univerze $v$ Ljubljani. Njeni raziskovalni področji sta ekonomika zdravstva in ekonomika javnega sektorja. Sedanje raziskovalno delo vključuje proučevanje učinkovitosti in uspešnosti izvajalcev zdravstvenih storitev $v$ Sloveniji in proučevanje inovacij kot dejavnika učinkovitosti in uspešnosti bolnišnic $v$ Sloveniji. Trenutno je članica Sosveta za zdravje Statističnega urada Republike Slovenije. Sodelovala je pri razvoju magistrskega študija Management in ekonomika $v$ zdravstvenem varstvu, ki je nastal s pomočjo sredstev EU in je prvi tovrstni program $v$ Sloveniji. Objavila je članke, $v$ katerih analizira in proučuje različne vidike slovenskega zdravstvenega sistema in reforme ter politike $v$ tem sektorju. Sodeluje $v$ svetovalnih projektih na področju zdravstva $\vee$ Sloveniji.

Dr. Maks Tajnikar je redni profesor na Katedri za ekonomsko teorijo in politiko na Ekonomski fakulteti Univerze $v$ Ljubljani. Bil je minister za malo gospodarstvo (1992-93) in minister za gospodarstvo (1993-96) Republike Slovenije. V obdobju 2001-2007 je bil dekan Ekonomske fakultete. Objavil je več kot 230 strokovnih in znanstvenih člankov, učbenike (Mikroekonomija, Upravljavska ekonomika, Tvegano poslovodenje, Postkeynesianska ekonomska teorija), je avtor 5 knjig in soavtor 5 knjig. Njegova raziskovalna področja so podjetništvo, ekonomika javnega sektorja in ekonomika zdravstva. Sodeloval je pri razvoju magistrskega študija Management in ekonomika v zdravstvenem varstvu, ki je nastal s pomočjo sredstev EU in je prvi tovrstni program $v$ Sloveniji. Trenutno je tudi vodja tega programa na Ekonomski fakulteti. Objavil je članke, $v$ katerih analizira in proučuje različne vidike slovenskega zdravstvenega sistema in reforme ter politike $v$ tem sektorju. Sodeluje v svetovalnih projektih na področju zdravstva v Sloveniji in je član Sveta Kliničnega centra Ljubljana. 
Petra Došenovič Bonča, Maks Tajnikar

Model presoje poslovne uspešnosti in izkoriščenosti

zmogljivosti $v$ bolnišnicah

\section{Literatura in viri}

- Anyanwu, K., Sheth, A., Cardoso, J., Miller, J. \& Kochut, K. (2003). Healthcare enterprise process development and integration. Journal of Research and Practice in Information Technology, 35(2), 83-98.

- Harmon, P. (2007). Business process change: a guide for business managers and BPM and Six Sigma professionals. ( $2^{\text {nd }}$ ed.) Amsterdam etc.: Elsevier/Morgan Kaufmann Publishers.

- Hollingsworth, B., \& Peacock, S. (2008). Efficiency measurement in health and health Care. London, New York: Routledge.

- Kornai, J., \& Eggleston, K. (2001). Welfare, Choice, and Solidarity in Transition. Cambridge: Cambridge University Press.

- Lenz, R. \& Reichert, M. (2007). IT support for healthcare processes - premises, challenges, perspectives. Data and Knowledge Engineering, 61(1), 39-58.

- Navodilo o beleženju in obračunavanju zdravstvenih storitev. Najdeno 19. julija 2009 na spletnem naslovu http://www.zzzs.si/ZZZS/info/egradiva.nsf/

- Ould, M. (1995). Business processes: modelling and analysis for re-engineering and improvement. Chichester: John Wiley.

- Ozcan, Y.A. (2008). Health care benchmarking and performance evaluation: an assessment using data envelopment analysis (DEA). New York: Springer, cop.

- $\quad$ Phelps, C.E. (2003). Health Economics. (3 ${ }^{\text {rd }}$ ed.) Boston: Addison Wesley.

- Poulymenopoulou, M., Malamateniou, F. \& Vassilacopoulos, G. (2003). Specifying workflow process requirements for an emergency medical service. Journal of Medical Systems, 27(4), 325-335.

- (2008a). Področni dogovor za bolnišnice za pogodbeno leto 2008 - Priloga IX. Ljubljana: Zavod za zdravstveno zavarovanje Slovenije.

- $\quad$ (2008b). Splošni dogovor za pogodbeno leto 2008. Ljubljana: Zavod za zdravstveno zavarovanje Slovenije.

- (2008c). Področni dogovor za bolnišnice za pogodbeno leto 2008. Ljubljana: Zavod za zdravstveno zavarovanje Slovenije. 


\section{SUMMARY}

\section{BUSINESS PROCESS MODEL AS A TOOL TO ASSESS BUSINESS PERFORMANCE AND CAPACITY UTILIZATION IN HOSPITALS}

Business performance analysis and assessment is usually performed using various indicators of performance in both ratio form or as indicators in absolute values. Such indicators of business performance are often coupled with indicators of efficiency that reflect the levels of utilisation of available resources. Efficiency indicators help explain indicators of performance. The paper demonstrates that business performance analysis based on standard business performance indicators can be improved for the case of hospitals if one views the hospitals as process organisations when analysing their business performance and efficiency.

The paper thus demonstrates that the assessment of business performance of hospitals has to be based on a business process model of the studied hospital. Such business processes have to reflect the flows of patients from the point of their entry into a hospital to the point of their exit from the hospital upon completion of their treatment. Patient flows are determined by the treatment processes they undergo. During their treatment the patients pass through hospital's various organisational units. The patient's treatment process engages capacities of several units, departments or clinics of a hospital and also capacities of other providers of health care services in case a hospital refers a patient to a different health care institution for additional services. Because the patient's treatment process engages various human and material capacities of a hospital it also creates costs on the one hand and the right of a hospital to claim payments from the insurers and create revenue in line with the implemented payment system for health care services. Treatment processes that determine the flows of patients through the hospital's organisational units are the hospital's core processes. This means that from all business processes carried out by a hospital the treatment processes contribute most significantly to the outcome of the patient's care. The hospital's treatment processes are thus the hospital's value-adding processes. There are several other business processes a hospital carries out to support its core treatment processes. Such support processes or enabling processes do not contribute to creating additional value directly. However, they create 
Petra Došenovič Bonča, Maks Tajnikar

Model presoje poslovne uspešnosti in izkoriščenosti

zmogljivosti v bolnišnicah

costs and have to be accounted for in business performance analysis and allocated correctly to the performance of core treatment processes.

A business process model of a hospital that is used to analyse and assess its business performance consists of the following elements:

1. detailed list of hospital's organisational units;

2. number of patients entering each analysed hospital's organisational unit based on a referral from other health care organisations or without a referral (entry as a first contact with a hospital)

3. number of patients entering each analysed organisational unit based on a referral from other hospital's organisational units

4. standards for delivery of care for each analysed organisational unit that determine the needed quantity of human and material capacities per patient and therefore determine both the needed total quantity of human and material capacities

5. total quantity of available human and material capacities of each analysed organisational unit.

Business performance assessment of hospitals that is based on a business process model of the studied hospitals entails two phases. In the first phase we have to model the hospital's business processes and develop a model of business processes that shows patient flows between hospital's organisational units and patient flows that link the hospital to other health care organisations. The purpose of this first phase is to define the processes and determine their interdependence and also to quantify the activities that comprise the processes. Results of the first phase can then be used in the second phase to obtain two results that provide information about the hospital's business performance. The first result shows the capacity utilisation rates for both human and material capacities engaged during the delivery of hospital's core processes. The second result demonstrates the achieved business performance of core processes aggregated at the level of individual organisational units.

Both results provide guidelines for business process change that contributes to increased efficiency and lower costs. Analysis of capacity utilisation rates can also be used to implement organisational changes that enable smoother patient flows and reduce bottlenecks and excess capacities. Analysis of capacity utilisation rates is thus necessary to determine employment needs and needs for new investments and also those excess 
Petra Došenovič Bonča, Maks Tajnikar Model presoje poslovne uspešnosti in izkoriščenosti zmogljivosti v bolnišnicah

capacities that create costs but cannot contribute to outcomes of care and hospital's revenues.

Detailed allocation of incurred costs to hospital's organisational units that is based on patient flows or treatment processes enables the determination of business performance on the level of individual organisational units. Such an analysis enables us to determine which units create losses and which are the ones that contribute to the creation of profits. Such an analysis that is based on determining the links between core and support processes also enables us to allocate the costs created by the support processes more accurately to the core processes and units that carry them out. In addition, the analysis of business performance that is based on a model of business processes enables us to develop several measures of performance. First, we can determine the performance that shows the relation been the incurred costs and revenue created by payments from insurers and other payers. Second, we can determine the performance taking into consideration the interdependence of various organisational units and both actual revenues and revenues created by internally charging transfer prices.

Assessment of business performance based on a model of business processes that links the analysis of business performance to the analysis of capacity utilisation also enables us to determine the causes of poor or good performance. Causes of poor performance can be internal or external. There are two main internal causes. The first internal cause is inappropriate standards for delivery of care for each analysed organisational unit that determine the needed quantity of human and material capacities per patient. The second internal cause is underutilised human and material capacities. The external cause of poor performance relates to the inappropriate payment system for health care services. If, for example, a certain organisational unit fully utilises human and material capacities and has appropriate standards for delivery of care, then we can attribute poor performance to inadequate prices set for delivery of health care services. The prices and the payment system set for the provision of health care services are a nondiscretionary factor that cannot be influenced by the hospital's management. The above discussion shows that the analysis of business performance based on a model of business processes identifies the causes of poor performance that can be influenced by the management, the measures that need to be taken to tackle poor performance and those causes that are external and represent a nondiscretionary factor of poor business performance. 